\title{
EDQM-HC Combined Term Terminology
}

National Cancer Institute

\section{Source}

National Cancer Institute. EDQM-HC Combined Term Terminology. NCI Thesaurus.

Code C150105.

Terminology subset about single terms to describe a pharmaceutical dose form (or combined pharmaceutical dose for) and an item of packaging, either for the purpose of disting uishing between marketed products that differ only in the container or administration device, or where the item of packaging has special characteristics that are relevant to the use of the medicinal product. 